\title{
La intertextualidad en el seno de la cibercultura
}

\section{María Goicoechea de Jorge}

\section{(2) OpenEdition}

\section{Journals}

Edición electrónica

URL: https://journals.openedition.org/cher/2742

DOI: $10.4000 /$ cher.2742

ISSN: 2803-5992

\section{Editor}

Presses universitaires de Strasbourg

\section{Edición impresa}

Fecha de publicación: 27 junio 2017

Paginación: 75-85

ISBN: 978-2-86820-961-0

ISSN: 1968-035X

\section{Referencia electrónica}

María Goicoechea de Jorge, «La intertextualidad en el seno de la cibercultura», reCHERches [En línea] 18 | 2017, Publicado el 01 diciembre 2021, consultado el 17 diciembre 2021. URL: http:// journals.openedition.org/cher/2742 ; DOI: https://doi.org/10.4000/cher.2742

\section{(c) (i) (-)}

Ce(tte) œuvre est mise à disposition selon les termes de la Licence Creative Commons Attribution Pas d'Utilisation Commerciale - Partage dans les Mêmes Conditions 4.0 International. 


\title{
La intertextualidad en el seno de la cibercultura
}

\author{
María GoICOECHEA de JoRGE*
}

These fragments I have shored against my ruins

(1. 430, The Waste Land, T.S. Eliot)

\begin{abstract}
T a cibercultura, ese entramado de comportamientos, intercambios, Lexperiencias, conocimiento, técnicas, valores y creencias que se han ido sedimentando en torno al uso del ordenador y del ciberespacio, es un fenómeno complejo cuya madeja se extiende más allá de los medios digitales y cuya influencia reconfigura nuestro modo de comprender el mundo y de relacionarnos, también fuera de línea. La irrupción de internet en la ecología de medios de comunicación ha transformado el equilibrio y el rol que los distintos medios desempeñaban hasta ese momento, obligando a una nueva reinvención de sus funciones. En relación a la literatura, se profetiza el fin del papel ante la llegada del medio electrónico, sin embargo a menudo esta confrontación entre lo digital y lo impreso olvida que lo impreso ya es digital y que lo digital en muchos casos no es más que una extensión-remediación de lo impreso. Por otro lado, la cibercultura se nutre no solo de lo que acontece dentro de las redes ciberespaciales, sino también de lo que se respira en las calles, los museos, se dibuja en los cómics, se devora en papel o se escucha en la radio. Desde los primeros esbozos que William Gibson hiciera de un ciberespacio en su novela Neuromante en 1984, hasta el tercer brazo del artista australiano Stelarc, pasando por los estimulantes artículos de la revista Wired, la cibercultura ha sido creada también por un entramado de medios que han situado en su centro la reflexión en torno a la interacción hombre-máquina y la capacidad de la tecnología para crear realidades virtuales en las que relacionarnos. Por tanto, pueden ser fruto de la cibercultura literaria tanto obras en papel como obras de una literatura concebida para ser leída fundamentalmente en el entorno digital.
\end{abstract}

* Profesora en el Departamento de Filología Inglesa II en la Universidad Complutense de Madrid (UCM) y miembro de LEETHI (UCM) y de HERMENEIA en la Universidad de Barcelona. 
Para esta breve aproximación acerca del papel de la intertextualidad en el seno de la cibercultura, se contemplarán distintos géneros de escritura característicos de la misma. Por un lado, empezaré por analizar el modo en que obras de la ciencia ficción ciberpunk en formato impreso abordan, desde la perspectiva que aporta el viejo medio, los miedos y ansiedades generados en torno al ciberespacio, como son la desorientación del lector en los laberintos ciberespaciales y la pérdida de unas coordenadas, tanto textuales como mentales, que aporten un contexto de lectura que sirva de guía. Por otro, comentaré el uso que se hace de la intertextualidad en uno de los géneros más comunes de escritura digital, el hipertexto, que en su versión más cotidiana suele redundar en una intertextualidad explícita, contribuyendo así a crear mayor sobrecarga informativa y desorientación. Y por último me gustaría mostrar algunas obras de la literatura digital en las que se juega con la intertextualidad para poner de relieve las rupturas y continuidades que se dan en la evolución hacia la textualidad electrónica. Como veremos, los distintos géneros literarios de la cibercultura, tanto en formato impreso como digital, aluden a las mismas cuestiones desde perspectivas diferentes y a menudo complementarias que nos hacen reflexionar sobre las transformaciones que se están dando en los pactos de lectura que unen a escritores, a textos y a lectores.

A modo ilustrativo, me gustaría comenzar describiendo una de las escenas que encontramos en Synners, una novela de ciencia ficción «cyberpunk» de la escritora norteamericana Pat Cadigan: Valjean, una especie de vampiro cibernético, tiene a una mujer de rehén en la terraza de la vigésima planta de un edificio. Se quiere arrojar con ella al vacío mientras busca en su cabeza el contexto correcto que dé sentido a tan desesperada acción. Su mente se ha trastornado por completo desde que se sometió a la operación de un implante cerebral que le permite conectarse directamente al ciberespacio. Dentro del espacio virtual, Valjean siente la unidad con el todo; él es un pensamiento más dentro de una red de conexiones en la que humanos y ordenadores se hallan fusionados. Todo parece estar en el contexto adecuado, incluso cuando este contexto no se puede determinar. Sin embargo, cuando está desconectado, no encuentra sentido a nada, utiliza a las personas como objetos sin subjetividad propia, como parte del escenario que él ha decidido vivir. Con la destrucción de su cuerpo (y el de la mujer) pretende eliminar su dualidad (esta división mente-cuerpo que le está torturando) y convertirse en tan solo un pensamiento, un nodo en la red.

Los personajes de Pat Cadigan experimentan a su manera los conflictos que el mundo digital introduce en la forma de concebir la identidad: como es el uso cada vez más extendido de conceptos que vienen del mundo de la informática para describir la experiencia humana (software-hardware/mentecuerpo; almacenaje de información/memoria, inteligencia artificial/capacidad mental, etc.), y el consiguiente desequilibrio al que se enfrenta el ser humano en un mundo modelado cada vez más por y para las máquinas. Bajo un barniz de novela de evasión y entretenimiento, Synners ofrece otro nivel de lectura cuya carga intertextual alude a las preocupaciones de la cibercultura académica. 
Lo mismo ocurre con otras novelas e historias cortas de la ciencia ficción «ciberpunk», como Snowcrash, Schismatrix Plus, o «Johnny Mnemonic».

Es precisamente en el uso que la ciencia ficción contemporánea realiza de la intertextualidad postmoderna donde podemos encontrar el origen del interés que el género ha despertado dentro de la cibercultura académica. En un nivel superficial, los textos de William Gibson, Bruce Sterling, Pat Cadigan o Neal Stephenson parecen adecuarse al patrón característico de las novelas de aventuras futuristas de la literatura de consumo (o «pulp fiction»): una fuerza maligna amenaza con controlar todo el planeta (o planetas habitados por el ser humano), mientras que uno o varios héroes, normalmente accidentales y mal pertrechados, se enfrentan a ella con éxito. Tras esta estructura extremadamente simplificada, se esconden una serie de alusiones y guiños, detectadas con gusto por un lector ciberculto, a los principales temas debatidos en el seno de la cibercultura académica. La intertextualidad o alusión a otros textos, en este caso a textos canónicos de la cibercultura académica ${ }^{1}$, se combina con un estilo «pseudo-posmodernista» en la presentación de la narrativa (más marcado en Gibson y Cadigan que en otros autores): mediante la yuxtaposición de fragmentos, el uso de metalepsis transgresoras, discontinuidad, pluralidad de voces narrativas, etc.

Entre los temas de la ciencia ficción ciberpunk que conciernen a la cibercultura académica se encuentran la figura del ciborg, el posthumanismo, el problema del contexto, la inadecuación de la memoria humana frente a los nuevos modelos informáticos para el almacenamiento de datos, la sobrecarga de información y la lectura subliminal, las nuevas posiciones del sujeto en la realidad virtual, la división mente/cuerpo, el paradigma informático como nueva representación tecnicista del ser humano, la revisión histórica de la tecnología de la información, la geometría de los fractales, el tecnopaganismo, etc.

El relato breve de William Gibson «Johnny Mnemonic» (1986) es uno de los ejemplos que mejor ilustra esta interrelación entre la creación literaria y las preocupaciones académicas. Curiosamente, Gibson sugiere que los ordenadores en su obra son simplemente una metáfora para la memoria humana (no su alternativa). En este relato, Gibson recrea en la figura de Johnny Mnemonic la visión del sujeto posthumano que puebla la cibercultura; un ser que, gracias a su hibridización con la tecnología, ha conseguido convertirse en algo más que humano. Aplicando de modo creativo los paradigmas de la informática a su historia, Gibson utiliza el concepto informático de «memoria» en la transformación de su personaje principal.

En el lenguaje informático, la memoria se entiende como un mero mecanismo de almacenamiento y recuperación. Desde este punto de vista mecanicista, el

1 Por ejemplo, «Como podríamos pensar» («As we may think») de Vannevar Bush, «Manifiesto para ciborgs: ciencia, tecnología y feminismo socialista a finales del siglo Xx» de Donna Haraway, «La Nueva Economía Informacional» de Manuel Castells, o «Inteligencia Colectiva» de Pierre Lévy. 
«recordar» es un proceso en el cual el agente puede estar «ausente», ya que no requiere de un procesamiento consciente ni del tamiz de la comprensión. Adoptando esta nueva perspectiva, Johnny Mnemonic hace uso de esa máquina biológica sobre la que tiene dominio, su cuerpo, y alquila su cerebro en calidad de espacio mnemotécnico para información sumamente confidencial.

El conflicto está servido. "Johnny Mnemonic» es la historia de un hombre que intenta recuperar el dominio sobre su cuerpo, sobre su memoria. Lo que guarda es peligroso aun cuando él desconoce su contenido $\mathrm{y}$, por haberse convertido en mero envoltorio de mensajes que no le pertenecen, su vida corre peligro. Mientras que la trama de la historia es sencilla, la lectura de este relato dista mucho de serlo. El lector tiene pocas coordenadas con las que orientarse en el nuevo universo creado por Gibson. Uno de los factores que más desorienta al lector es el uso de numerosos neologismos para los que no se provee un referente claro. Sin embargo, los lectores de Gibson reconocen el vocabulario de una novela o historia a otra (términos relacionados con su particular geografía urbana: Chiba City, los barrios marginales de The Sprawl o Night City, los tugurios como The Drome o The Chatsubo; o con su tecnología: el «Ono-Sendai» o consola con la que conectarse al ciberespacio, los «cowboys» o piratas informáticos, los "geodesics» o los cristales acrílicos que forman la gigantesca cúpula bajo la que se haya la ciudad, etc.). Así, es quizá en el terreno de la retórica en el que la ciencia ficción escapa de los convencionalismos, dirigiendo la atención a su capacidad para inventar nuevas palabras y jugar con el lenguaje. Es también aquí donde la literatura de ciencia ficción establece su especial campo de juegos intertextual (o más bien intratextual), mediante la creación de un lenguaje que carece de referentes en la realidad. El léxico de la ciencia ficción constituye un universo de nuevos significantes para los que no existen significados actuales, creando un paradigma de referentes ausentes. Esta intertextualidad se alimenta de una retórica de la ausencia, pues todo aquello para lo que el lector no encuentra referente real queda subrayado, y se abre el terreno a la participación activa del lector, creando múltiples juegos de palabras y parodias de la realidad.

-Can you read my mind...Wintermute?

-Minds aren't read. See, you've still got the paradigms print gave you, and you're barely print literate. I can access your memory, but that's not the same as your mind. (Neuromante: 165)

En una de las obras canónicas de la cibercultura, también de William Gibson, Neuromante, la inteligencia artificial Wintermute es capaz de acceder a la memoria de Case, el personaje principal, y reconstruirla en un holograma tan preciso que el mismo Case no puede distinguirlo de sus recuerdos. Wintermute, el superordenador, manipula la reconstrucción de los recuerdos de Case para sus propios propósitos. De este modo, Gibson crea una analogía entre la «objetividad» de la tecnología informática y el funcionamiento "subjetivo» de la memoria humana. Aunque podría considerarse que Gibson utiliza 
la inteligencia artificial para representar una característica de la psicología humana (la inteligencia artificial sería la conciencia, el superego), y no tanto el funcionamiento de las máquinas reales, lo relevante aquí es que las construcciones virtuales de recuerdos producidos por la máquina parecen competir con los recuerdos humanos. Desde el punto de vista semiótico, en el relato de Gibson las representaciones de la máquina son «textos» que rivalizan en el grado de modalidad con las construcciones mentales de los humanos. Si la realidad tiene autores, la máquina parece ser un escritor cuyos mensajes reciben mayor credibilidad y fiabilidad.

Esta reflexión, que la novela de ciencia ficción ha integrado en su trama, aparece encarnada en la estructura misma de las redes hipertextuales de Internet. La intertextualidad mecánica que se utiliza en la mayor parte de los hipertextos que tejen la red compite con la intertextualidad evocada por la mente del lector. En este punto nos encontramos con un choque abrupto entre las expectativas del lector tradicional acerca del texto y las nuevas instancias de enunciación narrativa que se le proponen a través del funcionamiento del hipertexto. El hipertexto trae consigo una nueva economía de lectura y escritura, en la que los principios que en un momento sirvieron para dar cuenta del fenómeno literario, como la evocación de la memoria y la creación durante la lectura de horizontes de expectativas (Iser y Jauss), deben reformularse.

En particular, uno de los temas que preocupa a críticos y escritores de la cibercultura es la desorientación del lector en los laberintos ciberespaciales, un mal que la intertextualidad explícita del hipertexto trata de resolver pero que a menudo incrementa. Si nos fijamos en el entramado de textos que constituye Internet (las listas de resultados de los buscadores, los blogs, los portales, las wikis, etc.) podemos ver que el uso que se realiza de los enlaces a menudo apunta hacia una intertextualidad unívoca y sin pasado. Si Kristeva utilizaba el concepto de intertextualidad para desbancar la idea de texto como unidad autónoma de significado, aislado de otros textos, las redes hipertextuales por un lado parecen haber encarnado este entramado de relaciones, pero al hacerlas explícitas, reproducen de nuevo la idea de que el texto puede ser autónomo, ser autoexplicativo ad infinitum. La escritura hipertextual incorpora a la vez el texto y su contexto, formando una especie de constelación de textos en medio de un ciberespacio donde ya no es posible dar por hecho un entramado intertextual en el que escritores y lectores converjan en un pasado común de lecturas. Dado que su «hábitat» natural es el ciberespacio, el hipertexto es un tipo de escritura proyectada hacia un futuro de lectura incierto, y por ello, carga explícitamente con todas las referencias intertextuales que su autor considera necesarias. Este uso de la intertextualidad se convierte no ya en el pasado del texto sino en su eterno presente, compitiendo con la intertextualidad libre evocada por el lector, al cual se presupone desmemoriado. La necesidad de un contexto de lectura en el que integrar la información del hipertexto se vuelve redundante pues el hipertexto es ya una unidad autosuficiente y autoexplicativa. 
Paralelamente, el lector de ciencia ficción experimenta una carencia de información contextualizadora durante la lectura del texto futurista, pues lo desconoce todo sobre el tipo de universo en el que se integran los acontecimientos narrados. El escritor debe encontrar mecanismos mediante los cuales su lector pueda construir una diégesis sin caer en una explicación demasiado explícita de su mundo imaginario. En ambos modelos de escritura, hipertexto electrónico o ciencia ficción impresa, el autor delimita las construcciones mentales del lector mediante la aportación de un contexto intratextual hecho explícito (los enlaces hipertextuales o las extensas descripciones de las sociedades futuras). En ambos casos también, la habilidad del ciberlector para interpretar de manera satisfactoria el texto depende en gran medida de su familiarización con el manejo de los ordenadores. En la ciencia ficción ciberpunk, una fuerte carga intertextual recae sobre las alusiones al mundo ciberespacial: sus rutinas, códigos informáticos, virus, prácticas comunicativas, piratería, etc. Sin embargo, mientras que la estructura de muchos de los hipertextos que pueblan la red parece obviar la necesidad de aludir a la memoria colectiva de una comunidad de lectores (pues puede añadir al texto todo tipo de apéndices, convirtiendo la memoria del lector en un recurso obsoleto), la literatura de ciencia ficción depende en gran medida de la familiaridad de sus lectores con el género para ser reconocida como tal (Stockwell 2000: 7).

Si bien el recuerdo de lecturas pasadas parece haber sido relegado a un segundo plano entre las habilidades imprescindibles del ciberlector, el establecimiento de relaciones intertextuales continúa siendo una vital estrategia de lectura dentro del ciberespacio, pues qué duda cabe que no todos los lectores manejan con el mismo grado de facilidad las convenciones del nuevo medio. Por tanto, cuanto mayor sea la familiaridad del lector con las potencialidades de la textualidad electrónica mayor será su grado de asimilación de las nuevas convenciones de lectura. Ya en 1994 George Landow destacaba la importancia de estas convenciones y proponía a los autores de hipertexto e hipermedia utilizar un conjunto de técnicas que permitiesen a los lectores procesar la información que se les presentaba, invitándoles a redactar una retórica del hipertexto en la que se hiciese frente a los principales problemas con los que aún hoy se encuentra el lector: la falta de orientación les impide leer eficazmente y extraer placer de la lectura; la falta de información respecto a qué tipo de datos va a aportarles cada enlace, les hace tropezar con fragmentos ya leídos o no requeridos; lo que se resume en una falta general de información respecto al funcionamiento del hipertexto para que el lector pueda sentirse cómodo dentro de él. No obstante, también es importante destacar que para el avezado ciberlector descubrir estas constricciones sobre la marcha constituye en sí mismo parte del placer que la exploración de un hipertexto aporta.

Una mayor familiaridad con la lectura de hipertextos repercute en el desarrollo de una competencia literaria que permite al lector construir con más facilidad mapas mentales de la estructura en red del hipertexto. También se aprende a evitar la redundancia prestando atención a las pistas sobre la 
navegación que ofrece la pantalla del ordenador (si se reconoce la dirección de un enlace antes de que se cargue la página y el lector no quiere volver a ella, puede parar y retroceder con rapidez, etc.). Lo que llamaríamos alfabetización de la pantalla. Sin embargo, cuando la intertextualidad del hipertexto acaba por bloquear la intertextualidad libre evocada por el lector, podemos decir que el lector se ha visto sobrecargado de información y no ha sabido leer correctamente el texto. La sobrecarga de información parte de la base de que el lector se enfrenta con un excedente de información nueva que no sabe desechar o contextualizar en una estructura integradora.

En realidad, la tendencia hacia una intertextualidad explícita cada vez más recargada ya era la tónica general en los textos impresos, tanto académicos como literarios. El estilo académico se caracteriza por un apoyo sin precedentes en las citas como forma de dar peso y credibilidad a los argumentos que se presentan. Este requisito, heredado del método científico positivista, convierte la acumulación de conocimientos en estilo. En el plano artístico, el uso barroco de alusiones intertextuales es una de las características de la prosa modernista y postmodernista, desde el Ulysses de Joyce al Gravity's Rainbow de Pynchon.

En este sentido, los lectores cultos ya poseen las herramientas necesarias para lidiar con un exceso de relaciones intertextuales que no siempre puede reconocer, y a pesar de ello disfrutar de la lectura. Una de las estrategias es el cambio de modo de lectura hacia una lectura un tanto subliminal, en la que el lector pasa por alto gran número de detalles a la espera de encontrar su contexto o sentido más tarde. Para el avezado ciberlector, la información encontrada en la Red a menudo no produce una sobrecarga de información sino que se vuelve redundante. Esta redundancia solo es obvia para aquel que es capaz de recordar y de buscar siguiendo unos objetivos y dentro de un contexto de lectura determinado. De hecho, la intertextualidad como estrategia de lectura se convierte en un valioso recurso para poder hacer frente a lo que aparentemente pueda parecer una sobrecarga, puesto que sirve para contextualizar rápidamente la información en una estructura de conocimientos que se dan por supuesto. Así llegamos a la paradoja de que la intertextualidad es al mismo tiempo la causa y la solución de lectura en un mundo cada vez más saturado de información.

La paradoja se disuelve cuando observamos que la causa de sobrecarga es producto de la intertextualidad que procede del texto y la solución integradora proviene de las conexiones intertextuales que realiza el lector en su mente, y de ahí que la memoria de otros textos es una de las virtudes que tradicionalmente se han valorado de un lector profesional. El acto de leer o escribir está irremisiblemente unido al acto de recordar, de reconstruir. Ambos ejercicios conllevan una serie de operaciones mentales de difusas fronteras; la ficción es una memoria imaginada, la memoria una ficción cuidadosamente construida. La ficción, como extensión del ser humano, se convierte en un simulacro de la memoria que refleja la evolución de nuestras preocupaciones sobre la capacidad humana de recordar. 
Sin embargo, frente a las múltiples realizaciones del hipertexto, el lector se enfrenta a un problema de sobrecarga de información que le incita a aproximarse a la facultad de la memoria no ya en términos de sus virtudes evocativas sino de sus limitaciones. Entonces, con el fin de apuntalar la memoria del lector, numeroso hipertextos revierten en una sobrecarga informativa todavía mayor. Como nos advierte la ficción de Gibson, hemos pasado de entender el pensamiento como el hilo de una narración a concebir la memoria como una función de mero almacenaje, fácilmente sobrecargada, o simplemente una incómoda y temible característica de nuestras mentes. La estructura del hipertexto admite a un lector olvidadizo a la vez que le une en relación de dependencia con la máquina, que asume una carga intertextual cada vez mayor.

Como podemos ver, la intertextualidad, tanto como estrategia de escritura como de lectura, adquiere nuevas connotaciones ante la llegada del hipertexto. La intertextualidad forma parte del terreno de juegos del escritor en su particular relación con los lectores. Dar por hecho ciertos conocimientos comunes permite no solo establecer una relación de intimidad entre ambos sino también llevar a cabo la comunicación con una gran economía de medios. La escritura literaria se ha caracterizado por la explotación de los sobreentendidos a pesar de que no sea este el modo más sencillo de transmitir información, especialmente cuando el texto es culturalmente lejano para el lector. Sin embargo, es un elemento fundamental del placer de la lectura. La lectura literaria, como la definen Beaugrande y Dressler, se basa no en el uso del mínimo esfuerzo, sino en la proporción adecuada entre el esfuerzo requerido para la interpretación y la iluminación resultante («resulting insights», Beaugrande/Dressler 1981: 213), y por tanto se alimenta del juego de evocación de un pasado textual en el que gran parte del contenido del mensaje no se hace explícito. ¿Significa entonces el hipertexto la muerte de este tipo de intertextualidad literaria?

La respuesta a esta pregunta depende del uso que cada escritor haga de las posibilidades que le ofrece la escritura hipertextual en particular y la textualidad electrónica en general. Hasta ahora nos hemos referido al hipertexto como un género de escritura electrónica característico de la Red sin distinguir entre sus distintas manifestaciones. Debemos, sin embargo, matizar que la intertextualidad explícita de los hipertextos informativos característica de los hipertextos de no ficción, como las enciclopedias o los periódicos en línea, en los que el enlace se utiliza como modo de expandir la información relativa al nodo señalado, desaparece cuando se trata de hipertextos literarios. Como muy bien ha estudiado Susana Pajares Tosca, el hipertexto literario hace un uso totalmente diferente de los enlaces, potenciando su capacidad para la evocación poética:

Se podría decir que el hipertexto, al obligarnos a un reajuste de implicaturas ante la incertidumbre que suponen los enlaces, le añade una dimensión interpretativa extra a la lectura. Este "exceso interpretativo» es lo que nos hace hablar de la cualidad lírica de los enlaces (Pajares Tosca 2004: 111). 
El escritor del hipertexto literario juega también con la relación entre el esfuerzo de procesamiento y el efecto cognitivo en el que «la satisfacción del lector de enlaces no depende de que sus expectativas se cumplan exactamente, sino de que su búsqueda de relevancia se vea recompensada con efectos contextuales valiosos» (Pajares Tosca 2004: 114). A menudo, sin embargo, los autores de hipertextos literarios juegan y subvierten las expectativas del lector respecto al uso habitual de los enlaces: creando enlaces a partir de palabras inapropiadas (como en The Unknown de Scott Rettberg et al.), transformándolos, no en un ejercicio de elección por parte del lector ante caminos que se bifurcan, sino en el único modo de avanzar una narración (como en Twelve Blue de Stuart Moulthrop), construyendo contextos triviales, redundantes o totalmente desprovistos de sentido (como en Hegirascope, también de Moulthrop). A menudo se juega con una estética de la frustración que dificulta la lectura y reproduce la sensación de inadecuación del lector humano frente a los rizomas electrónicos. En otras ocasiones, como en el breve relato hipertextual de Belén Gache, "Mujeres vampiro invaden Colonia del Sacramento», los enlaces son el medio mediante el cual el lector parece tener un papel en la construcción del relato, entreverando las historias de las tres mujeres vampiro, Celeste, Jezabel y Camila, pero en seguida se da cuenta de la circularidad del hipertexto y su redundancia.

Si bien la estética de los enlaces ha recibido gran parte de la atención de la crítica como encarnación de las relaciones intertextuales e intratextuales del texto digital, la literatura digital está plagada de ejemplos de collages intertextuales en los que la reutilización de material de otros autores y otras fuentes adopta una miríada de formas en los que la imaginación del autor parece ser el único límite. El medio digital se enarbola como la materialización del ideal de las literaturas de vanguardia, especialmente de los experimentos modernistas, como podemos ver en el poema visual de Guillaume Apollinaire, «Il pleut», en su reedición digital realizada por Gregory Vincent St. Thomasino y Mary Ann Sullivan en 2008. En esta recreación multimedia del poema vemos el modo en que la programación informática ha conseguido dar el movimiento de las gotas de lluvia a las letras e incorporar el sonido de la lluvia en el desarrollo del poema. Otro modo de rendir homenaje a los antecesores de la literatura digital lo encontramos en la obra de Jim Andrews, On Lionel Kearns (2004), en la que el poeta digital canadiense hace un tributo al poeta Lionel Kearns que ya en 1965 dedicó su poema visual «Birth of God/uniVerse» al lenguaje binario. Andrews recoge en su pieza la obra original de Kearns y toda una constelación de textos relacionados con ella, incluyendo su propia reescritura electrónica del poema, un e-mail de una profesora preguntándole a Kearns sobre el significado de su obra, y la contestación de este. La obra de Andrews es en sí misma un microcosmos en el que se plasman las nuevas relaciones que el medio digital ha establecido entre tradición literaria, texto, escritor y lector.

Otro ejemplo interesante en el que la estrategia intertextual constituye la base de la obra es «Escribe tu propio Quijote» de Belén Gache. Con la concisión 
que caracteriza la obra de Gache, los efectos que esta pequeña obra digital crea en el lector reverberan con gran riqueza de matices tras haberla experimentado. Tras un prólogo en el que la autora reflexiona sobre nociones como la autoría y la identidad textual, con alusiones a la obra de Andy Warhol, Do it yourself flowers, y el cuento de Borges, «Pierre Menard, autor del Quijote», nos reta a que escribamos nuestro propio Quijote. Al introducirnos en la obra se abre una pantalla de un procesador de textos con un documento en blanco titulado «El ingenioso hidalgo Don Quijote de la Mancha». Tras superar el vértigo que produce el reto, el visitante que se anime a escribir se dará cuenta de que cualquier movimiento del teclado invariablemente irá escribiendo, palabra a palabra, el original de Cervantes, que será leído de un modo absolutamente nuevo por parte del lector.

Para una mejor evaluación de las promesas del nuevo medio es fundamental tener en cuenta en qué se basan los logros del antiguo. Como expresa el crítico alemán Peter Matussek (1998), el texto literario rompe, mediante el juego de evocación que establece con el lector, los límites de su propia textualidad como mera tecnología para el almacenamiento de datos. El arte de la literatura se convierte en una técnica deconstructiva de la propia función mnemotécnica del texto. Precisamente, la cualidad evocadora del texto literario surge del espacio que se abre entre líneas, de entre la hojarasca de palabras que apuntan hacia lo que no está escrito. Así pues, el escritor recurre a una estética de la ausencia, que es a la vez un silencio fecundo y cuajado de promesas, ya que cuenta con la complicidad del lector y su libre asociación de ideas para completar el texto. Como nos recuerda Proust, el conocimiento del lector comienza allí donde termina el del escritor: «Somos conscientes de que nuestra sabiduría empieza donde la del autor termina, y quisiéramos que nos diera respuestas cuando todo lo que puede hacer es incitar nuestros deseos» (Proust 1905: 36). Sin embargo, ¿cuándo empieza nuestra sabiduría en un texto que nunca termina o que rápidamente desaparece antes de que nos haya dado tiempo a leerlo?, ¿perecerá el lector en un frenesí de lectura inacabable, o por el contrario, se desesperará buscando un texto que no acaba de materializarse?, ¿cómo se puede calibrar un texto cuando este nunca acaba de realizarse, y su mensaje definitivo parece estar siempre un click más allá? Es en este punto en el que las obras de literatura digital marcan la diferencia entre un uso de la intertextualidad que empobrece o aquel que crea nuevos e inesperados efectos literarios. Pues para que las nuevas textualidades electrónicas puedan ser realmente artísticas y literarias deben encontrar sus propios límites y subvertirlos. 


\section{Bibliografía}

Beaugrande R.-A. (de) y Dressler W. U., 1981, Introduction to Text Linguistics, London, Longman.

Cadigan, P., 1991, Synners, New York, Four Walls Eight Windows, 2001.

Gibson W., 1984, Neuromancer, New York, Ace Science Fiction.

Gibson W., 1986, «Johnny Mnemonic», in: D. Trend (ed.), Reading Digital Culture, Malden, Mass., Blackwell, p. 57-69.

Matussek P., 1998, «Literary Recollection: The End(s) of Intertextuality» in: Th. Wägenbaur (ed.), The Poetics of Memory, Tübingen, Stauffenberg, p. 399-408. (Titelanzeige Literaturwissenschaft, 1-8) <http://www.petermatussek.de/Pub/A_22.html>). [Consulta: 15/01/14]

Landow G.P., 1994, "What's a Critic to Do?: Critical Theory in the Age of Hypertext?», in: Hyper/Text/Theory, Baltimore, Johns Hopkins University Press, p. 1-48. Traducción al español: (1997): «¿Qué puede hacer el crítico? La teoría crítica en la edad del hipertexto», Teoría del hipertexto, Barcelona, Paidós.

Orihuela J.L., 1999, «El narrador en ficción interactiva. El jardinero y el laberinto», Quién cuenta la historia. Estudios sobre el narrador en los relatos de ficción y no ficción, Pamplona, Ediciones Eunate, AAVV. <www.ucm.es/ info/especulo/hipertul/califia.htm> [Consulta: 01/01/14].

Pajares Tosca S., 2004), Literatura digital. El paradigma hipertextual, Cáceres, Universidad de Extremadura, Servicio de Publicaciones.

Proust M., 1905, Sobre la lectura, Manuel Arranz (trad.), Valencia, Pre-Textos, 1996.

Stephenson N., 1992, Snowcrash, New York, Bantam Books.

Sterling B., 1996, Schismatrix Plus, New York, Ace Books.

Stockwell P., 2000, The Poetics of Science Fiction, Harlow, Longman, Pearson Education Limited. 